\title{
Marcadores sociais da diferença e sentimentos no universo LGBT maputense
}

\author{
NELSON ANDRÉ MUGABE \\ Universidade do Estado do Rio de Janeiro, Rio de Janeiro, Rio de Janeiro, Brasil
}

DOI 10.11606/issn.2316-9133.v28i2p306-324

resumo Este artigo analisa marcadores sociais da diferença produtores de hierarquias, desigualdades e discriminações entre pessoas LGBT na cidade de Maputo. A análise das intersecções de gênero, classe social, idade e sexualidade demonstra que os sujeitos LGBT em certos contextos de sociabilidades constroem hierarquias e formas de discriminação entre si, que por sua vez geram sentimentos tais como a humilhação, a vergonha e o desprezo. A pesquisa é de carácter etnográfico e baseou-se nos métodos e técnicas tradicionais da antropologia: observação participante e conversas informais com sujeitos LGBT.

palavras-chave Homossexualidades; Sujeitos LGBT; Marcadores sociais da diferença; Emoções.

\section{Social markers of difference and feelings in the LGBT universe in Maputo}

abstract This article analyzes social markers that produce hierarchy, inequality and discrimination among LGBT individuals in Maputo. The analysis of gender and its intersection with social class, age and sexuality demonstrates that LGBT individuals in the context of social relations build hierarchies and forms of discrimination, which in turn generate feelings such as humiliation and the contempt. The research is ethnographic and was based on the traditional methods and techniques of anthropology: participant observation and informal conversations with LGBT individuals.

Keywords Homosexualities; LGBT individuals; Social markers of difference; Emotions. 


\section{Apresentação}

No presente artigo analiso como os marcadores sociais da diferenças constroem hierarquias, desigualdades e sujeitos (in)desejáveis nas relações sociais entre pessoas pertencentes ao universo LGBT ${ }^{1}$. O seu recorte empírico inclui, gays, lésbicas e "travestis" maiores de 18 anos que residem na cidade de Maputo, Moçambique. A geração de dados foi feita pela combinação de observação participante em circuitos de sociabilidades LGBT, conversas informais e entrevistas semi-estruturadas, entre janeiro e maio de 2014.

Para alcançar esse objetivo, o progresso teórico que adoto procura se distanciar dos trabalhos que se limitam a explicar que as instituições sociais heterossexuais são as que discriminam e geram preconceitos contra homossexuais, para inscrever a minha discussão num corpo de literatura crescente que, ao analisar as relações sociais LGBT em contexto de sociabilidades, mostra a existência de marcadores sociais da diferença que operam para a produção de sujeitos (in)desejáveis entre os mesmos no que diz respeito aos seus desejos e preferências sexuais; discriminação dos menos favorecidos social e economicamente; e dos que denotam performances de gênero consideradas "excessivas" (MARSIAJ, 2003; HENNING, 2008; VEGA, 2008; FACCHINI, 2008; SIMÕES et al, 2010).

No entanto, como forma de ir além da perspectiva analítica dos marcadores sociais da diferença, inspirado por pesquisadores das emoções, entre outros Barbalet (1998) e Rezende e Coelho (2010) - que demonstram a centralidade da emoção nas relações sociais dos indivíduos -, apresento como sentimentos tais como o nojo, o desprezo, a vergonha e a humilhação são acionados nos circuitos de sociabilidades e nas preferências sexuais dos sujeitos LGBT. Na confluência destas duas perspectivas, argumento que os marcadores sociais da diferença no universo LGBT de Maputo evocam diferenças, desigualdades e produzem distintas moralidades e sentimentos particulares.

Este artigo está estruturado em duas partes, além das considerações finais. $\mathrm{Na}$ primeira, através dos relatos dos interlocutores, discuto as circunstâncias em que os marcadores sociais da diferença emergem nas relações sociais no universo LGBT e os sentimentos que são mobilizados. $\mathrm{Na}$ segunda parte, busco analisar as narrativas dos interlocutores sobre como o gênero é um marcador que cria desigualdade, hierarquia e exclusão de certos sujeitos nas relações sociais LGBT, bem como aciona convenções sociais no processo de produção dessa diferença.

\footnotetext{
${ }^{1} \mathrm{O}$ texto é baseado em minha dissertação de mestrado intitulada Marcadores de diferença e jocosidade entre sujeitos LGBT na cidade de Maputo, desenvolvida com o apoio de bolsa do CNPq junto ao Programa de PósGraduação em Ciências Sociais, do Instituto de Ciências Sociais, UERJ sob orientação da Prof.a Maria Claudia Pereira Coelho e coorientação do Prof. Bruno Dallacort Zilli. O objetivo da dissertação foi analisar os marcadores sociais da diferença como criadores de hierarquias, discriminações e sujeitos (in)desejáveis nas relações sociais entre LGBTs e, ainda, estudar a dinâmica de interações jocosas constatando os eixos de diferenciações, subjetividades e valores acionados nas relações de brincadeiras.
} 
MUGABE | Marcadores sociais da diferença e sentimentos no universo LGBT maputense | 308

\section{Marcadores sociais da diferença e "rebaixamento" moral: humilhação e desprezo entre sujeitos LGBT}

Nesta parte do artigo discuto como no universo estudado a diferença é produzida e como se dá a transformação dos marcadores da diferença em indexadores de desigualdade e preconceito nas relações sociais entre pessoas LGBT. Esta discussão segue as orientações de teóricos que discutem os marcadores sociais da diferença na área das homossexualidades e que nos mostram as interseções de geração, gênero, classe nos diferentes estilos de sociabilidades "GLS" e mesmo no âmbito dos "movimentos homossexuais" (FRANÇA 2006, 2007; HENNING 2008; VEGA 2008; SIMÕES et al. 2010). Mas também é meu intuito aqui abordar os sentimentos particulares destacados nas falas dos interlocutores à luz de estudiosos das emoções (BARBALET, 1998; REZENDE; COELHO, 2010).

Os autores que em suas pesquisas entrecruzam as homossexualidades com outros marcadores sociais da diferença têm como mérito desvendar as hierarquias sociais, desigualdades, relações de poder, e discriminações vigentes no seio dos circuitos de sociabilidades e movimentos sociais LGBT. Este artigo insere-se na mesma linha desses autores, que recorrentemente constatam que os locais de sociabilidades voltados ao público LGBT também são afetados pelas desigualdades e diferenciações económicas, de gênero e idade que acabam discriminando e hierarquizando alguns sujeitos.

Em "Os campos de extermínio da desigualdade", Göran Therborn (2010) examina as maneiras pelas quais as desigualdades são produzidas nas relações sociais e distingue os termos "diferenças" e "desigualdades". Para ela, as diferenças podem ser horizontais sem que ninguém esteja acima ou abaixo socialmente de um ou de outro, sendo apenas questões de gosto e/ou de categorização; em contrapartida, a desigualdade é sempre vertical, é uma categorização que viola uma norma moral de igualdade entre seres humanos, além de serem diferenças hierárquicas, evitáveis e moralmente injustificadas.

Diante disso, no universo desta pesquisa, alguns sujeitos pertencentes ao universo LGBT na cidade de Maputo têm um ideal implícito de que a orientação sexual deveria unilos, não devendo existir hierarquias, formas de preconceitos e desigualdades internas entre eles, uma vez que são grupos minoritários e discriminados por instituições sociais tais como igrejas, estado, sociedade e família. Essa percepção é acionada por homossexuais de extratos sociais e economicamente baixos, por "travestis", "lésbicas masculinizadas" e "gays efeminados".

Como explica Therborn (2010), as desigualdades sociais são prejudiciais para as vidas humanas e para a vida em sociedade. Pois algumas desigualdades criam o distanciamento entre as pessoas, outras restringem a liberdade de ação de certas categorias de pessoas, geram humilhações para os grupos subalternizados em suas condições de vida e modos de existência.

Apropriando-me das teorizações deste autor, constatei que nos contextos de sociabilidades LGBT, as diferenças entre pessoas LGBT produziam desigualdades existenciais e materiais sobre aqueles rotineiramente classificados de "gays efeminados", 
"travestis", "lésbicas masculinizadas", além daqueles identificados como sendo de posições sociais inferiores e ou economicamente baixas. Como consequência, as desigualdades no universo em estudo geram o estiramento da distância social entre as pessoas LGBT, diminuem a coesão social, o que, por sua vez, gera o desejo em certas pessoas LGBT de se ausentar dos convívios ou contextos de sociabilidades LGBT.

Algumas pessoas LGBT que situavam casos de discriminação em suas vidas estão cientes das diferenças presentes em suas relações sociais e destacam sentimentos particulares em consequência dessas diferenças desiguais entre "iguais". Isso porque eles têm uma convicção de que a orientação sexual deveria uni-los, para além de quaisquer outros marcadores como a classe social (poder aquisitivo), o grau de escolaridade e operadores sociais como o estilo. Porém, de acordo com os relatos, isso não ocorria. Estes marcadores e operadores sociais da diferença acabam criando hierarquias e discriminações, gerando sentimentos de rebaixamento ou de interiorização como humilhação, vergonha e desprezo. A esse respeito, a narrativa de Fábio $^{2}$, jovem de 19 anos de idade e pertencente a estratos médios-baixos, é esclarecedora:

Nelson: olha gostaria de saber se é possível falar-se da existência de discriminação entre os homossexuais masculinos aqui na cidade de Maputo. Qual a tua opinião sobre o assunto?

Fábio: É verdade, aqui existe e é muito vergonhoso, é muito triste ver isso. Já somos discriminados e ainda nós nos discriminamos entre nós.

Nelson: Poderia explicar o que leva alguns a discriminar os outros?

Fábio: Aqui há homossexuais, do tipo, que tem um nível social mais elevado que o meu, não vão se envolver ou criar amizade comigo mesmo eu me aproximando deles. Você vê que querem pessoas do mesmo nível, eles preferem se relacionar com pessoas que têm as mesmas condições. São coisas que acho que não deveria existir. Essas coisas de divisão em termos de nível de condições, de instrução escolar, mas existem muito entre nós, os gays. Muitas vezes aqueles que têm instrução social elevada gostam de humilhar os que são de baixo. Do tipo tu és muito brega, não tens nada, estás abaixo, não entendes nada. Então, para mim aqui existem aqueles que brincam entre si, os de cima, os da classe $\mathrm{A}$, tem amizade entre eles, os da classe $B$, tem amizade entre si e da $C$ também entre si.

Nelson: Aé? Como você identifica que fulano pertence à classe A, B, C? O que é isso de classe A, B, C e o que eles têm?

Fábio: Pela forma de vestir, o tipo de roupa que usam. Assim, conheces o Tirso, posso dizer que ele é da classe $\mathrm{A}$, o Edson parece que também é dessa classe. Mas o Tirso é muito social e simples, mas se fosse o Edson ou

\footnotetext{
${ }^{2}$ Os nomes dos interlocutores presentes neste texto são fictícios.
} 
outras pessoas que brincam com eles não iam se envolver conosco sem muitas condições. Mas Tirso é muito social, não tem nada a ver com isso de ser superior, ele ri com todo mundo, para ele as pessoas são iguais, mas outros nem querem saber. As pessoas que têm condições frequentam sítios como Ace Lange, um sítio chique. Edson é considerado a rainha desse sítio.

Nelson: O que fazem esses outros?

Fábio: Esses nem um olá te dizem, mesmo quando você lhe diz olá, ele responde com desprezo. Pior quando tem carro, mesmo te vendo ele passa-te, mas você diz: "eu conheço aquela pessoa, frequentamos as mesmas festas, temos a mesma orientação sexual, ele me conhece. Você lhe manda um olá, finge que não te viu e nem está ai”.

(Entrevista com Fábio, 10 de março de 2004, grifos meus)

Este depoimento mostra o quanto as relações sociais entre os gays são afetadas pela diferenciação, de tal modo que os marcadores de classe social, no sentido de poder aquisitivo e vestimentas, orientam as relações de amizades entre gays. Depreendo também da narrativa de Fábio que os sujeitos com maior poder aquisitivo são percebidos como humilhando, envergonhando e desprezando gays com condições financeiras mais limitadas. Assim, aqueles com maior poder aquisitivo, ao provocar sentimentos de vergonha e humilhação no outro, são retratados como visando rebaixar e inferiorizar os gays de estratos económicos mais baixos.

Por conta disso, alguns gays de estratos económicos mais baixos muitas vezes expressam, em seus relatos, percepções de si mesmos como rebaixados e inferiores diante daqueles com melhores condições económicas. Eles demonstram, por vezes, sentimentos de tristeza e de vergonha por causa desse nível de diferenciação baseado em classe e estilo, que desconsidera que todos têm a mesma orientação sexual.

Como explica Katz (2013, p. 238), tanto a vergonha quanto a humilhação são emoções sociais e morais, no sentido de que, em ambas, as pessoas se sentem isoladas de uma comunidade vista por elas como sagrada. Na humilhação, as pessoas supõem uma intenção ostensiva e consciente dos outros de desejarem rebaixá-las socialmente. Ademais Katz sugere que a humilhação é um sentimento holista e que denota a criação de uma hierarquia: "a humilhação põe para baixo; na humilhação você se sente subitamente diminuído, tão diminuído que o mundo inteiro parece olhá-lo de cima” (KATZ, 2013, p. 239).

Nesse sentido, o como e o porquê de alguns sujeitos LGBT humilharem e sentirem vergonha dos outros e/ou se sentirem humilhados e envergonhados, podem denotar, no universo desta pesquisa, relações sociais em que estão em jogo hierarquias, relações de poder, moralidades e dinâmicas de inclusão/exclusão, que atingem a identidade de alguns interlocutores LGBT na medida em que demarcam distinções sociais entre eles. A conversa 
a seguir com o jovem, Valter de 28 anos de idade expressa também alguns sentimentos particulares:

Valter: As separações de classe social que cria desprezo entre nós mesmos. Há homossexuais que discriminam Egídio pela sua vaidade, do tipo "ele não precisa de aquilo ele é homem", mas os discretos devem entender que um homossexual tem hormonas femininas. Alguns homossexuais discriminam a forma de outro homossexual se comportar, do jeito que se apresenta, do tipo são muitos efeminados. Por exemplo, não que eu falei isso para as travecas, mas ouço gays a dizerem que não posso andar com travecas, elas são bregas, não precisavam colocar cabelo, vestido, salto, porque elas não são mulheres. Eu sou afeminado e ouço pessoas a dizerem "você não precisa fazer isso". Mas eu não gosto de viver para agradar as pessoas, gosto de me agradar primeiro e depois os meus amigos. Os gays discretos às vezes me encontram e dizem: "não precisa pintar as unhas com base". Ora dizem que: "não vão andar mais comigo", mas eu digo a eles: "é minha vaidade". Sabes esses toques que alguns homossexuais dizem são exagerados é que fazem com que nós os outros sermos felizes, ter coragem e aumentar a nossa autoestima. Outra coisa que cria divisão entre nós é a forma de vestir o estilo da roupa. Manas gostam de rebaixar os outros quando se trata de roupa.

Nelson: Como o estilo de vestir cria separações entre vocês?

Valter: existe muita intriga entre os homossexuais, despreza-se a alguém porque usou roupa mal combinada ou vestiu um tipo de roupa que comprou na baixa, que são vulgares. Uns dizem que aquele é muito brega, e isso ofende. Eu vou comprar aquelas roupas da baixa porque é o que eu consigo, mas há pessoas que dizem: "Ah! eu não posso andar com Cardoso ou ser amigo do Jack porque veste coisa que compra na rua", aquelas roupas que ficam na esquina, na baixa, e se calhar vale apenas eu que uso e consigo comprar essas roupas. Porque algumas pessoas que se dizem que usam roupa da marca vivem de aparência, as pessoas andam a contrair dívidas ou a pessoa pede emprestado para parecer bonita, para aparecer da classe A, fingir muito bem que está nessa classe, enquanto na verdade onde ele dorme você nem vais olhar duas vezes. Acontece que alguns gays vivem muitos de cala de boca, por exemplo, se eu fosse outro não teria te levado para minha casa.

(Entrevista com Valter, 16 de abril de 2014, grifos meus)

Neste fragmento de entrevista vemos uma narrativa que mostra alguns elementos que criam segregação, hierarquização e discriminação nas relações sociais no universo gays, 
segundo Valter: o poder aquisitivo e o estilo de vestir. Valter expressa também a questão do desprezo decorrente dos eixos de diferenciação entre os gays a partir da ideia implícita acima de que a orientação sexual deveria se superpor às diferenças de classe social e estilos.

Como argumentam Rezende e Coelho (2010), alguns sentimentos emocionais como nojo, desprezo e humilhação realizam entre os níveis micro da experiência pessoal e macro da organização social um trabalho micropolítico, permitindo hierarquizar as relações sociais. Em outra passagem, Rezende e Coelho (2010, p.85), acompanhando as ideias de Miller (1997) explicam que, tradicionalmente, o desprezo é um sentimento que emerge em relações hierárquicas, sendo devotado por quem ocupa as posições superiores àqueles em situação inferiorizada.

Entretanto, na conversa com Valter, percebo que certos atributos desqualificados por homossexuais "discretos" são indispensáveis para a constituição da subjetividade e da identidade de certos gays, pois no caso dele lhe possibilitavam ser corajoso e orgulhoso: "esses toques que alguns homossexuais dizem ser exagerados é que fazem com que nós, os outros, sermos felizes, ter coragem, aumenta a nossa autoestima”. Assim, no discurso de Valter, está presente o sentimento de coragem e o orgulho que resulta do fato dele poder vivenciar a sua subjetividade e identidade.

Ademais, pude perceber em conversas com outros interlocutores gays de Maputo o acionamento das emoções que geram ações. Assim, alguns sentimentos como orgulho e vergonha nessas relações sociais trazem à tona uma vontade para agir: por exemplo, quando há uma profunda compreensão do poder aquisitivo dos outros, as pessoas gays de extratos econômicos baixos podem ocultar a sua situação social e familiar para os outros e copiarem os estilos de vestir e acessórios similares com dos gays que têm poder aquisitivo; ou frequentam certos locais de sociabilidades vistos como sendo de pessoas com poder aquisitivo como uma forma de se distinguir dos outros gays.

Além disso, ainda alguns homens gays com maior poder aquisitivo podem ceder aos marcadores sociais da diferença e usarem estilos de roupas e acessórios populares quando são considerados bonitos. No contexto em estudo, os estilos de roupas são operadores das diferenças entre os gays com maiores poderes aquisitivos e dos que têm menores, mas também abrem espaços para a agência de alguns gays com menores poderes aquisitivos, quando estes copiam os estilos de vestir dos com maior poder aquisitivo como forma de adequação social.

Por seu turno, no universo das lésbicas de Maputo, as suas relações sociais são também permeadas por marcadores sociais como classe social, gênero e graus de escolaridade bem como por operador de diferença, o estilo, que criam hierarquias e colocam certas mulheres no polo de valorizadas e outras no de desvalorizadas. Consequentemente, aquelas que se sentem desvalorizadas nas relações sociais evitam contatos sociais com outras lésbicas devido às diferenças que criam desigualdades entre elas. 
Entretanto, como explica Goffman (2011, p.104), "o individuo que mais se isola de contatos sociais pode então ser o menos isolado das exigências da sociedade". Na esteira da análise simmeliana e goffmaniana, Coelho (2013, p.14) explica que "é ao recusar/afastar-se do contato com o outro que o indivíduo atestaria sua natureza social: o social se faz presente consigo mesmo no ato de embelezamento de si ou por via de resmungos ou imprecações, assinalando a possibilidade de comunicação sem diálogo”.

Trago esse pensamento goffmaniano subscrito por Coelho (2013) como forma de explicar que a atitude das lésbicas de estratos médios-baixos, em sua fuga de relações com outras mulheres que denotam alto poder aquisitivo e ostentam marcas de roupas, é compreensível, pois a forma como se diferenciam acaba por constrangê-las, gerando um senso de inferioridade, de desrespeito e de tornar-se "estranha" junto às pessoas com a mesma orientação sexual. Como consequência, algumas lésbicas se abstêm de estabelecer relações com outras percebidas como de estratos superiores. Tal como os gays mencionados acima, as lésbicas de estratos médios-baixos criam uma expectativa implícita de que a orientação sexual se superponha a marcadores sociais da diferença. A conversa a seguir com Tomázia uma jovem de 22 anos esclarece esse ponto:

Nelson: Na nossa conversa anterior você falou da relação que tens com outras lésbicas e você disse que existe desigualdade entre vocês. E que você não tem muitas amizades com elas. É isso mesmo?

Tomázia: Sim, é verdade, como te falei existem diferenças entre nós. Eu até não entendo por que, mas o que acontece é que só por veres a pessoa, já dá para avaliar em que condição a pessoa está. Então, acho que elas se escolhem mais por aí. Olham a pessoa e vê a situação em que a pessoa se encontra.

Nelson: Que situação se olha?

Tomázia: Por exemplo, a situação financeira, muito mais financeira, é muito mais por aí. A maioria das festinhas que têm sido organizadas para a comunidade está mais cheias de grupinho, como você percebeu no dia da praia. Quando estávamos sentados todos juntos, algumas meninas começaram a fazer uma contribuição, mas como eu não tinha condição de fazer essa contribuição de certa maneira acabei me afastando do convívio porque não tenho condições de estar nesse espaço.

Nelson: Pela tua fala quem se distancia é você e não o grupo que se distancia de você. É isso que acontece?

Tomázia: Eu diria que o grupo também se distanciou de mim, os que não tinham condições. Por exemplo, aquele dia da praia tentei estar mais próximo, mas de repente as pessoas que estava ao meu lado saíram em grupo para comprar algo e a mim nem disseram nada. Apenas se 
MUGABE | Marcadores sociais da diferença e sentimentos no universo LGBT maputense | 314

chamaram entre si, então, eu achei muito feio a atitude, eles saíram porque têm condições, então fica mal eu sair e buscar coisa para comer e ficar perto de ti sem nada. Para mim entre as lésbicas existe desprezo por causa das questões do bolso, e isso cria divisões entre os que têm e os que não têm.

Nelson: Questão de bolso?

Tomázia: Sim, a questão do dinheiro. Como bem disse, a pessoa quando olha para ti já faz uma análise do tipo "esse aqui não tem nada”, e cria-se distância dos que podem e dos que não podem, por aí. E eu não sei por que isso acontece. Por isso eu fico na minha, não ando atrás das pessoas que não me querem por perto. Eu tentei criar amizade com algumas lésbicas, mas acabo ver por vezes que só pelo olhar delas não me querem por perto.

Nelson: Como consegues perceber pelo olhar que algumas lésbicas não te querem por perto?

Tomázia: O olhar diz tudo, como se costuma a se dizer, a imagem fala mais que mil palavras. Estás a perceber. Até nas conversas com elas, eu vejo que existem lésbicas que têm tendência de ficar no canto delas em grupos, as patricinhas. Você procura falar com elas, e é como elas não te ouvissem, mas não é isso é porque olha para tua forma de vestir, de falar, essas coisas. (Entrevista com Tomázia, 20 de abril de 2014)

Nesta narrativa mostra-se o quanto certos marcadores sociais da diferença como classe social informam as relações sociais entre lésbicas, gerando desigualdades e desconfortos para pessoas com menor poder aquisitivo. Nota-se que elas criam suas relações de convivência a partir de condições económicas e de certos estilos, que atuam na produção de hierarquia e segregação através de olhares que projetam desprezo e que transformam os que não têm condições económicas em sujeitos invisíveis na interação social. Outro aspecto referenciado por esse universo que rebaixa a moral dos outros e de certa forma inferioriza algumas lésbicas é a escrita ou fala fluente do português /ou nível de instrução escolar. A conversa com a jovem, Laura de 23 anos é expressiva nesse sentido:

Nelson: Que coisas são essas que levam algumas lésbicas a se considerarem superiores? O que elas têm?

Laura: Às vezes porque tem carro, outro não tem, ora porque trabalha e outros não, por aí, e isso acaba criando diferenças, porque se fores a ver, tem níveis sociais, há divisão em níveis sociais. Aqueles que têm brincam entre si, os que não têm a mesma coisa, mas acho que isso, não deveria existir, pois somos todos iguais, mas se somos os primeiros a criar esses 
preconceitos entre nós que somos minorias sexuais, então o que a maioria vai fazer.

Nelson: Como assim preconceito entre vocês? Explique isso.

Laura: É meio difícil a convivência entre as lésbicas por causa daquela coisa. "Ah! eu tenho isto, aquela não tem. Então não posso me envolver com ela”. Tu chegas, a pessoa sai, não quer conviver, não quer estar onde tem pessoas que se vestem mal. Por isso, eu acabo não criando muitas amizades com lésbicas. Num sítio onde tem muitas pessoas ou num grupo há pessoas que querem se achar superior. Assim, por exemplo, estive num grupo do Facebook de lésbicas que se discriminam em termo de nível escolar, a partir da forma da escrita, porque têm lésbicas que não sabem escrever corretamente, então eu acho que se eu vejo que você não sabe escrever, tem um fórum próprio para chamar atenção e não ao público, ou desvalorizar a pessoa até se sentir humilhado. A pessoa deve ter modo de falar do tipo: "olha é assim", pela maneira que a pessoa se dirige a pessoa pode entender. Mas se eu falo: "ah! você é burra, sei lá o que é essas coisas. A pessoa não gostará dessa agressividade. Então um dia desses no grupo de Facebook eu escrevi Camões com S, e sem acentuar, porque meu telefone tinha problema de acentuação, então quem disse "sei lá o que" foi a Lygia, tipo, quer se fazer de superior e vai escrever errado a palavra explicação e colocou S ao invés de X. Depois, eu escrevi da forma correta, ela não respondeu mais, porque ali ela queria mostrar superior, e para mim você pode ser superior na tua casa.

Nelson: Ela quis se mostrar superior em termos de o quê?

Laura: Em termos de escolaridade, tipo, ela sabe escrever melhor que as outras. Então, nesse grupo havia uma moça que era baixa em termos de classe escolar, então a mesma pessoa que me chamou atenção disse, "estou a ver que há pessoas que precisam de formação, vamos abrir uma seção para ensinar as pessoas". Até que a iniciativa era boa porque há pessoas que devido às condições não vão à escola. Para mim não adianta a pessoa vir com sua superioridade, pois eu te corto logo, há aquela coisa de ter autoestima. Então, outras lésbicas se deixam ser espezinhadas porque a pessoa tem uma aparência chique, porque a pessoa pensa que não tem nada. Épa! Para mim não vale a pena, temos que nos respeitar, nada de pisar nas outras pessoas.

(Entrevista com Laura, 19 de abril de 2019, grifos meus)

Depreendo desta narrativa, a situação desconfortável que gera para algumas lésbicas o sentimento de humilhação e de inferioridade em face da interação social. Percebo que a 
escolaridade é usada como forma para se distinguir das outras ou para rebaixar e inferiorizar as outras. Entretanto, noto que algumas lésbicas consideradas inferiores - na semelhança do que ocorrem com alguns gays acima abordados - buscam criar autoestima para enfrentar os marcadores de diferenciação que perpassam as suas interações. A seguir, analiso como o gênero é um desses marcadores que cria desigualdade, hierarquia e exclusão de certos LGBT na cidade de Maputo, atentando para as normas sociais acionadas nesse processo de produção de diferenças.

De forma explícita, os discursos dos colaboradores da pesquisa mostram as desigualdades sociais associados ao gênero: tudo o que é excessivamente feminino é desvalorizado por parte dos "gays discretos" que performam uma masculinidade normativa e o que é excessivamente masculino é desvalorizado por parte das "lésbicas femininas" que performam uma feminilidade normativa. Como destacado por Donna Haraway (2004, p.209), o gênero é central para as construções e classificações de sistemas de diferença. Entretanto, em minha discussão pretendo ilustrar como o gênero e outros marcadores sociais são posicionados nas relações de hierarquia e de antagonismo entre sujeitos pertencentes ao universo LGBT na cidade de Maputo.

\section{O perigo do exagero: feminilidade e masculinidade}

Nelson: Em sua opinião, o que leva os gays a se discriminar ou ridicularizar os outros?

Octávio: Eu não discrimino ninguém, mas tem atitude que não dá para aceitar, enfim, mas nunca mesmo andaria com uma trava. Eu nunca neguei para quem me perguntasse o que eu sou, nunca, mas tem a parte do job, muita responsabilidade. Tenho colegas que sabem, mas também não dá você estampar na cara, a única pessoa que ando com ela, não sei porque, acho por ser figura pública, é Mead, mas temos muita intimidade, há amizade, mas (voz alta) andar na rua ou brincar com Deise, Tróia, Deusa, nada, por exemplo. Deise nos tempos não era assim, era homem. Quando digo homem, ele não sabia o que é por extensões de cabelo, não sabia o que é vestido, ele colocava calça, tudo de homem, mas de lá para cá, sai com roupa de mulher. Antes de 2008, 2010 eu podia andar com Deise, mas hoje eu digo não. Veja como Mead faz. Ela usar essas coisas quando é para atuar, porque ela é uma drag queen, mas no dia a dia veste coisas feminizadas sem exagerar, o que tu és não tens que mostrar para as pessoas até chegar à loucura de por cabelo. Come on (risos).

Nelson: Como assim loucura?

Octávio: Eu sou gay, gosto da minha vida, mas quando falo com as pessoas eu não falo que sou mulher. Eu digo que sou homem, mas aquelas não, 
falei que a Deise, primeiro antes de colocar uma calça legging colocava calça de homem, na faculdade dela não aceitava que ninguém lhe chamar de mulher para hoje ela virar trava e aceitar ser chamada de mulher, pôr sapato alto, usar até calcinha fio dental. Sinceramente, a pessoa até pode usar roupa feminina, já que a roupa é uma forma de se expressar, mas não deve fugir do padrão, usar fio dental é demais, onde a pessoa quer colocar o pênis, sinceramente não condeno, mas Hei! Não apoio, sabe tem certas coisas que as pessoas exageram mesmo acabam fugindo do padrão.

Nelson: Qual seria o padrão?

Octávio: O padrão de ser homossexual não é de colocar extensão, as travas estão a se enganar, elas não são mulheres e nunca vão ser; quando é homem é homem. Eu sou gay, mas não sou mulher. Eu nunca vou colocar roupa de mulher, espera, a não ser no carnaval. Lembro que coloquei roupa feminina no carnaval, mas isso foi entre amigos (voz alta), só amigo. Decidimos que no carnaval vamos fazer uma coisa diferente e por incrível que pareça os meus amigos que eram heterossexuais foram mais caprichados em vestir como mulher, mas como eu sou mais inclinado para tal não fiz isso, só coloquei uma coisa básica, mas eles não mataram da ponta dos pés para cabeça.

(Entrevista com Octávio, 23 de maio de 2014)

Esta narrativa mostra o lugar da identidade de gênero nas relações sociais entre gays e não é raro no universo analisado os atributos de gênero serem usados para estabelecer relações de amizades e para se diferenciar dos outros homossexuais considerados "escandalosos". No universo dos gays que performam uma masculinidade normativa existe o desprezo em relação às "travestis", devido às transformações que desenvolvem em seus corpos. Uma vez que elas se desfazem do corpo masculino para construir um corpo feminino, até no pensar e agir elas buscariam, na visão dos entrevistados, se assemelharem com as mulheres. Para esses homens, o corpo masculino, viril e "discreto" representa o positivo, aquilo que é valorizado no mercado erótico.

Como lembra Silva (1993, p.129), na sua etnografia clássica sobre travestilidades no contexto brasileiro, "todo o esforço do travesti visa fazer-se passar por mulher. Seus êxitos e motivo de orgulho estão contidos em tal possibilidade”. Para outras pessoas LGBT, essa busca incessante das "travestis" por tornarem-se mulheres gera desconforto, pois se considera como ideal dos homossexuais a busca pelo equilíbrio e temperança na forma como se expressam as identidades de gêneros; por isso, são desvalorizados e ridicularizados todos os homossexuais que promovem o "excesso" na forma de vestir e no uso de cosmético. Assim, gays "efeminados" e travestis são alvos de estereótipos. 
No universo de meus interlocutores existe um modelo ideal de aparência e apresentação corporal que dialoga com um modelo heteronormativo e a valorização do equilíbrio na apresentação corporal. Todavia, o equilíbrio e a busca pela temperança na apresentação de si orientam o campo erótico no mercado do desejo, uma vez que torna alguns sujeitos desejáveis ou indesejáveis. Porém, neste universo da pesquisa existem alguns gays "discretos" que consideram as atitudes das "travestis" um ato de coragem que merece consideração e respeito:

Vasco: Tem aqueles gays que quando estão numa festa ou num convívio falam mal das travestis, mas não é andar com alguém que vão me chamar de ladrão, posso ter amigo assim, mas eu não ser. O problema é medo de encarar, por isso, alguns dizem: "ah, não ando com trava, o que as pessoas vão pensar?”. Porque a pessoa é discreta, está ainda no armário, só é assumido para ele, e não para a sociedade é por isso que existe esse retrocesso de não querer se aproximar das travestis, falando de mim eu aplaudo as travestis, eu digo sim aquilo que é coragem, um homem que veste a mulher e que sai na rua com um salto e cabelo, mas as pessoas sabem que ele nasceu a vestir roupas de rapazes e de um dia para o outro passou a usar roupa de mulher e as travestis saem com roupa de mulher. Eu gosto de ver aquele tipo de gente (risos). Aquilo é coragem. Aquilo é o que se diz de visibilidade e não aquilo de dizer que eu sou assumido e ainda se esconder. É preciso se assumir para a sociedade.

(Entrevista com Vasco, 04 de maio de 2014).

No universo estudado, algumas pessoas LGBT têm, ao mesmo tempo, sentimentos de desprezo e admiração pelas "travestis". Geralmente, elas são consideradas extravagantes e sua companhia seria comprometedora; vistas como "trapaceiras", principalmente aquelas que se dedicam ao trabalho sexual, são também compreendidas como divertidas, alegres e corajosas uma vez que subvertem as convenções do gênero.

A pesquisa de Edward MacRae (1990), sobre o surgimento do "movimento homossexual brasileiro" no período da abertura política nos meados da década 80 explica que naquele contexto histórico e social "a maioria dos homossexuais nutrem profundo desprezo e antipatia pelas travestis. Em contrapartida as travestis consideram-se os verdadeiros homossexuais assumidos e sempre enfrentam as repressões mais violentas" (1990, p.54). No universo estudado, as "travestis" estão cientes do lugar marginal que ocupam nas relações sociais LGBT na cidade de Maputo e contrapõem-se aos seus críticos afirmando, no mesmo sentido com MacRae, embora com as devidas diferenças históricas, sociais e contextuais, que são os "verdadeiros homossexuais" e estão num estágio avançado de consciência identitária: 
Nelson: Como você se define no mundo homossexual?

Tróia: Olha eu sou um homossexual, mas uma travesti.

Nelson: Mas o que é ser travesti?

Tróia: O travesti é um tipo de homossexual que está numa fase avançada, já se assume como mulher, dentro de casa no ambiente social, qualquer espaço eu me sinto à vontade. Mas a nossa vida aqui é muito difícil, há muito preconceito e não somos representados, percebe.

Nelson: Mas se existe uma associação de minorias sexuais aqui em Maputo que defende os gays, lésbicas e travestis...

Tróia: Aquilo não é uma associação, é uma empresa que beneficia os gays que são discretos, que não têm coragem de assumir a cara. No inicio aquilo era muito bom, mas agora aquilo está a virar as moscas. Praticamente das pessoas que antes frequentavam comigo já não vão lá, sabe. Mesmo agora não conheço onde é que a nova instalação da Lambda, a maioria das travestis, não vão a Lambda, ninguém vai. Lá está mais de gays do que travestis. Nós não temos espaços lá. Os gays se mantem a distancia de nós. $\mathrm{Eu}$ particularmente não brinco muito com gays, minhas amigas são mulheres ou travestis.

Nelson: Conta-me da tua convivência com os gays.

Tróia: Olha, praticamente nós andamos entre nós, os gays não gostam de estar conosco, até falam mal, tem medo ou preconceito da gente porque vestimos a mulher, assim podemos comprometer a eles. Nós sempre, de dia vestimos assim, e eles vestem como homem. Não há intimidade. Só nas festas só. Os gays têm medo de assumir, por isso quando né, nós usamos vestidos, trançamos cabelo, usamos saias, eles se afastam... por acaso não são todos, mas a maioria. Eu conheço um gay que me disse abertamente que não podia andar comigo junto na rua porque não dá, mas as mulheres hetero elas brincam e andam comigo normalmente (...) o triste é ver uns gays discretos a falarem mal de nós, enquanto somos homossexuais.

(Entrevista com Tróia, 10 de maio de 2014)

Esta narrativa descreve a relação entre "travestis" e gays na cidade de Maputo e a invisibilidade das "travestis" na associação de minorias sexuais, a Lambda ${ }^{3}$. As "travestis" lidam com a dupla discriminação: uma advinda da sociedade e a outra dos próprios homossexuais. Entretanto, a discriminação advinda dos homossexuais é vivenciada como

\footnotetext{
${ }^{3}$ Associação LAMBDA é uma organização de cidadãos moçambicanos que advogam pelo reconhecimento dos direitos humanos das pessoas LGBT (lésbicas, gays, bissexuais e transexuais).
} 
dolorosa uma vez que estes sujeitos implicitamente entendem que a orientação sexual deveria se superpor às diferenças que geram desigualdades e segregação.

Entre as lésbicas deste universo, as chamadas lésbicas "masculinizadas" sofrem desqualificação e discriminação por parte daquelas que se adequam aos padrões de gêneros socialmente aceito na cidade de Maputo, e que consideram as mais "masculinas" como agressivas. Como dizem: "querem ser homem à força”. Por isso, a maioria das lésbicas "discretas" e "femininas" evita criar relações de amizades com outras que buscam, no mesmo sentido oposto, mas similar com as "travestis", desfazer-se do corpo feminino para construir um corpo masculino, até mesmo no pensar e agir, pois, segundo as lésbicas "femininas", as primeiras tentam se assemelhar com os homens em todos os aspectos.

Tanto a masculinização excessiva do corpo feminino quanto a ambiguidade da expressão de gênero de certas lésbicas são criticadas e desencorajadas, e não raro a companhia das lésbicas "masculinizadas" é vista como constrangedora e comprometedora. Em meu entender, a recusa de estabelecer relação e consequentemente a ridicularização, a discriminação das "travestis", dos homossexuais com excesso de feminilidade, das lésbicas "masculinizadas" e daquelas lésbicas "ambíguas"4 por parte dos gays e lésbicas "discretos", é uma estratégia de desviar o preconceito para subgrupos ainda mais vulneráveis no universo LGBT. Os extratos que seguem de entrevistas com Laura (23 anos) e Esmeralda (21 anos), respectivamente, ratificam este posicionamento para o caso das lésbicas "ambíguas" e "masculinizadas":

Laura: Eu, por exemplo, eu não sou masculina, gosto de certas peças masculinas, mas não que seja minha identidade. Então há aquela coisa, que no meu modo de vestir, posso ficar de short, amanhã uma calça jeans, sei lá, faço aquela rotação de vestir, visual, mas aquelas pessoas que te vê de um calção ou uma calça masculina, então, as outras comentam "tu tens que te definir ou queres ser isto ou queres ser aquilo". Eu acho que a maneira de vestir não identifica a sexualidade da pessoa, eu posso gostar de roupas masculinas enquanto não sou nunca fui de envolver-me com mulheres só estou a gostar daquela forma de vestir. Eu sou mais feminina pelo meu estilo de vestir, mas pela minha mistura acabo sendo interpretada como versátil, então as pessoas dizem: "ah você tem que se definir" e isso acaba me chateando. Elas não percebem que vestir é uma questão de gosto.

(Entrevista com Laura, 19 de abril de 2019)

$\mathrm{Na}$ mesma sequência da questão da expressão de gênero nas relações sociais entre lésbicas, Esmeralda, que performa uma feminilidade normativa, comentou nos seguintes termos:

\footnotetext{
${ }^{4}$ As lésbicas “ambíguas" são aquelas que usam roupa concebida com masculina e feminina alternadamente
} 
Esmeralda: Uma das coisas que me leva a não brincar com as lésbicas masculinas é que se criamos uma ideia entre nós e estamos a sair vamos conhecer muitas pessoas do tipo até que podemos nos encontrar com nossos familiares, tio, tia, então, essa que vestiu a homem sendo mulher vai denunciar nós todos, vê-la essas coisas, vão dizer o que de ti. Uma das coisas que também leva as lésbicas a discriminar as que vestem como homem é que elas criam um pênis imaginário, vai querer ser como um homem, tudo o que o homem faz, até na maneira de ser, aquele autoritarismo, vai querer seguir um padrão que um homem segue, mas isso está errado. Elas são mulheres, podem vestir calças, mas não podem esquecer que elas são mulheres, e elas esquecem isso.

(Entrevista com Esmeralda, 24 de março de 2014)

Estes trechos ilustram as motivações que levam algumas lésbicas à recusa de estabelecer relação com outras consideradas "masculinizadas", e ainda a desvalorizar a ambiguidade na expressão de gênero: é desejável que a lésbica adopte ou um estilo feminino ou um estilo masculino. A fusão dos estilos na forma de vestir gera confusão para as outras e consequentemente exercem pressão para que a ambígua se posicione ou no polo valorizado, que seria vestir-se como "feminina", ou no polo desvalorizado, que seria vestirse como "masculinizada".

Em geral, os marcadores sociais de classe social, gênero, estilo e com menor intensidade o nível educacional interferem no estabelecimento de relações sociais entre sujeitos LGBT na cidade de Maputo. Alguns desses marcadores são usados para desqualificar, discriminar as "travestis", os gays "efeminados" e/ou as lésbicas "masculinizadas" e hierarquizar as relações sociais. Contudo, o marcador social de gênero, para além de ser usado para facilitar ou dificultar estabelecimento de relações sociais com outros sujeitos pertencentes ao universo LGBT, juntamente com outros marcadores sociais, como a raça e a idade, orientam as preferências sexuais no universo desta pesquisa.

A análise das preferências sexuais mostra a produção de diferenças no seio dos interlocutores gays e lésbicas e a escala de valorização na busca de potenciais parceiros. Para os gays, os "discretos", as pessoas pretas e aqueles que estão na faixa etária de 20 a 25 anos de idade estariam no topo da valorização no desejo. Já para "efeminados" e "travestis", pessoas brancas e pessoas menores de 20 anos de idade estão na base da valorização do desejo.

Para as interlocutoras lésbicas, aquelas que performam uma feminilidade normativa e, consideradas adultas estão no topo da valorização do desejo erótico; contrariamente, as lésbicas que buscam a masculinização dos seus corpos, e consideradas adolescentes estão na base da valorização do desejo erótico. Contudo, reitero a capacidade de agenciamentos dos interlocutores do universo desta pesquisa: assim, podem existir pessoas LGBT que, mesmo 
MUGABE | Marcadores sociais da diferença e sentimentos no universo LGBT maputense | 322

preferindo os sujeitos do topo da valorização do desejo, se relacionam com pessoas que estão na base da valorização do desejo, e vice-versa.

\section{Considerações finais}

Este artigo analisou como se estabelecem as relações sociais entre sujeitos LGBT na cidade de Maputo e seu significado para aqueles que nelas participam. A estratégia analítica deste trabalho foi animada pela abordagem dos marcadores sociais da diferença. A partir dessa abordagem, demonstro como nas relações e interações sociais entre sujeitos LGBT se desenvolvem hierarquias e desigualdades a partir de poder aquisitivo, estilos, expressões de gênero e, ainda, discriminação contra lésbicas "masculinizadas", "travestis" e gays "efeminados".

Neste trabalho, mais do que mostrar as diferenças internas no universo de gays e lésbicas de Maputo, ilustrei que essas identidades separadamente criam regras e sentimentos morais que são entrecruzados por marcadores sociais da diferença como gênero, classe social, idade, escolaridade, gerando desigualdades que colocam certos sujeitos pertencentes ao universo LGBT no pólo de valorizados e desejados e outros no pólo de desvalorizados e indesejados. Como explica Biroli (2013, p.82), as identidades são feitas em meio a pressões, interpelações e constrangimentos que não são necessariamente percebidas como tal. Para Biroli, as convenções e constrangimentos sociais são vivenciados por indivíduos concretos e, no contexto deste estudo, são experimentados pelas "travestis", pelos "gays efeminados" e pelas "lésbicas masculinizadas".

Os gays "discretos" e as lésbicas "femininas", por um lado, orientam os seus julgamentos morais pelos padrões de moralidade hegemônicos, mas que lhes permitem criar formas de diferenciação alternativas que vão para além do par homo/hétero. Por outro lado, acionam uma ética e uma estética das formas adequadas de viver a homossexualidade sem desestabilizar as convenções de gêneros heternormativos.

Entretanto, as pessoas inferiorizadas não se submetem passivamente aos julgamentos e às formas de classificações alheias: elas apresentam leituras alternativas, ressignificando as diferenças. Assim, por exemplo, as "travestis" consideram que são os homossexuais "mais verdadeiros", que tiveram coragem de levar até as últimas consequências a subversão das convenções de gênero. Além disso, algumas lésbicas buscam estilos de roupas que lhes permitem fazer parte do mainstream daqueles que usam estilos valorizados. Todavia, dei pouca atenção analítica à agência daqueles que ocupam uma posição inferiorizada, que reagem e enfrentam as leituras estigmatizantes que lhes são impostas.

Assim sendo, o entrecruzamento das homossexualidades com marcadores sociais da diferença ou com as categorias interseccionais como gênero, classe social, idade, escolaridade seria, pensando com Biroli (2013, p.91), um atalho para um conjunto de estruturas que posicionam os indivíduos LGBT: definem constrangimentos morais e sentimentais que têm impactos negativos para alguns desses atores LGBT na cidade de Maputo. Contudo, como 
ensina Foucault, citado por Riot-Sarcey (2014), nas relações sociais existem relações de sujeição e resistências individuais e coletivas que os sujeitos agenciam em suas relações sociais. E neste trabalho pontuei a forma como as "travestis", os gays "efeminados" e as lésbicas "masculinizadas" se posicionam face às discriminações e humilhações internas.

Os argumentos mobilizados revelam elementos similares àqueles presentes na literatura especializada sobre gênero e sexualidade (cf. MARSIAJ, 2003; HENNING, 2008; VEGA, 2008; FACCHINI, 2008; SIMÕES et al, 2010). Apesar dessa similaridade, argumento que no universo estudado existe uma percepção de que sujeitos LGBT produzem rebaixamentos morais e sentimentos particulares que reafirmam hierarquias nas relações sociais, preferências sexuais e nos espaços de sociabilidades.

Estas relações sociais atravessadas por diferenciações mapeadas ao longo do texto geram entre gays e lésbicas de estratos médios-baixos sentimentos de impotência, inferioridade e um desejo de ausentar-se dos espaços de sociabilidades LGBT, devido ao desapontamento constante da expectativa de que a orientação sexual deveria ser elemento que une todos os sujeitos LGBT.

\section{Referências bibliográficas}

BARBATET, Jack. Emoções, teoria social e estrutura social: uma abordagem macrossocial. Lisboa: Instituto Piaget, 1998.

BIROLI, Flávia. Autonomia, opressão e identidades: a ressignificação da experiência na teoria política feminista. Revista Estudos Feministas, V.21, n.1. 2013. pp. 81-106.

COELHO, Maria Claudia. (Org.). Estudos sobre interação: textos escolhidos. Rio de Janeiro: UERJ, 2013.

FRANÇA, Isadora. Lins. Cercas e pontes: O movimento GLBT e o mercado GLS na cidade de São Paulo. Dissertação de Mestrado em Antropologia Social. São Paulo: PPGAS/USP, 2006

GOFFMAN, Erving. Constrangimento e organização social. In: Rituais de Interação. Petrópolis: Vozes, 2011. pp. 95-109.

HARAWAY, Donna. "Gênero um dicionário marxista: a política sexual de uma palavra". Cadernos Pagu, Campinas, n. 22, 2004. pp. 201-246.

HENNING, Carlos Eduardo. As Diferenças na diferença: hierarquia e interseções de geração, gênero, classe, raça e corporalidade em bares e boates GLS de Florianópolis, SC. (Dissertação de Mestrado em Antropologia Social). Santa Catarina: PPGAS/UFSC, 2008. KATZ, Jack. Massacre justo. In: COELHO, Maria Claudia. (Org.). Estudos sobre interação: textos escolhidos. Rio de Janeiro: UERJ, 2013. pp. 211-284.

MACRAE, Edward. A construção da igualdade: identidade sexual e política no Brasil da abertura. Campinas: EDUNICAMP, 1990.

MILLER, Willian Ian. The anatomy of disgust. Cambridge: Harvard University Press, 1997. 
MUGABE | Marcadores sociais da diferença e sentimentos no universo LGBT maputense | 324

MARSIAJ, Juan P. Pereira. Gays ricos e bichas pobres: desenvolvimento, desigualdade socioeconômica e homossexualidade no Brasil. Cadernos AEL, v. 10, n. 18/19, 2003. pp. 129-150.

REZENDE, Claudia Barcellos; COELHO, Maria Claudia. Antropologia das emoções. Rio de Janeiro: FGV, 2010.

RIOT-SARCEY, Michèle. Michel Foucault para pensar o gênero: sujeito e poder. In: CHAUBAUD-RYCHTER, Danielle; DESCOUTURES, Virginie; DEVREUX, AnneMarie; VARIKAS, Eleni (Org.). Gênero nas Ciências Sociais: Releituras críticas de Max Weber a Bruno Latour. Brasília: Ed. UNB, 2014.

SILVA, Hélio R. Santos. Travestis: a invenção do feminino. Rio de Janeiro: Relume-Dumará, ISER, 1993. pp. 553-568.

SIMÕES, Júlio Assis; FRANÇA, Isadora Lins; MACEDO, Marcio. Jeitos de corpo: cor/raça, gênero, sexualidade e sociabilidade juvenil no centro de São Paulo. Cadernos Pagu, vol. 35, 2010. pp.37-78.

THERBORN, Göran. Os campos de extermínio da desigualdade. São Paulo, Novos Estudos, vol. 87, 2010. pp. 145-156.

VEGA, Alexandre Paulino. Estilo e marcadores sociais da diferença em contexto urbano: Uma análise da desconstrução de diferenças entre jovens em São Paulo. (Dissertação de Mestrado em Antropologia Social). São Paulo: PPGAS/USP, 2008.

\section{Nelson André Mugabe}

É doutor e mestre em ciências Sociais, ambos pela Universidade do Estado do Rio de Janeiro, com graduação em Antropologia pela Universidade Eduardo Mondlane. 